\title{
HER2 Testing in Invasive Breast Cancer: A Comparison Between Immunohistochemistry and Fluorescence In Situ Hybridization Assays
}

\author{
Maryam Moradi Chaleshtori $^{1}$ (D, Zohreh Hojati ${ }^{1}$ (D), Ali Jazaeri² (D) Hossein Teimori $^{3^{*}}$ (D) \\ 1. Department of Biology, Faculty of Sciences, University of Isfahan, Isfahan, Iran. \\ 2. Department of Biology, School of Sciences, Shiraz University, Shiraz, Iran. \\ 3. Cellular and Molecular Research Center, Basic Health Sciences Institute, Shahrekord University of Medical Sciences, Shahrekord, Iran.
}

\begin{tabular}{|c|c|}
\hline $\begin{array}{l}\text { Use your device to scan } \\
\text { and read the article online }\end{array}$ & \\
\hline 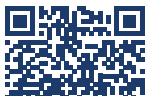 & $\begin{array}{l}\text { tween Immunohistochemistry and Fluorescence In Situ Hybridization Assays. Research in Molecular Medicine. 2020; 8(3):139- } \\
\text { 146. https://doi.org/10.32598/rmm.8.3.1133.1 }\end{array}$ \\
\hline 口iting & dol'https://doi.org/10.32598/rmm.8.3.1133.1 \\
\hline
\end{tabular}

\section{(c) (1) (8)}

Article Type:

Research Article

Article info:

Received: 11 May 2020

Revised: 17 Jun 2020

Accepted: 11 Jul 2020

Keywords:

Breast cancer, FISH, IHC, HER2

\begin{abstract}
A B S T RA C T
Background: HER2 status testing in breast cancer is crucial for the detection of eligible patients for trastuzumab therapy. In this study, the relative copy number of HER2 gene, in patients with breast cancer, was determined by Fluorescence in Situ Hybridization (FISH) and the results were compared with those of Immunohistochemistry (IHC) to obtain the concordance rate between these two methods.

Materials and Methods: HER2 status of 31 invasive breast cancer samples was compared using IHC and FISH techniques. The ratio of HER2/CEP17 was used to determine the amplification of the $H E R 2$ gene. If the ratio of HER2/CEP17 is greater than 2.2, HER2 gene amplification has occurred in the cancer cells. Then, a comparative analysis is performed to estimate the concordance rate between FISH and IHC results.

Results: The gene amplification of HER 2 was observed in $26 \%$ of cases by FISH. The IHC and FISH results showed $100 \%, 36.36 \%$, and $85.71 \%$ concordance rates for cases with IHC scores of $3^{+}, 2^{+}$, and $0 / 1^{+}$, respectively. The overall concordance between the two methods was $80 \%$. Based on statistical analysis, HER 2 status showed a considerable correlation with tumor grade $(\mathrm{P}=0.02)$. No correlation was observed between HER2 gene status and the size and type of tumor, characteristics of lymph node, and patients' age.

Conclusion: The data suggested that IHC results are reliable for HER2 status testing in cases with IHC scores $0 / 1^{+}$and $3^{+}$. However, in patients with an IHC score of $2^{+}$, it is necessary to perform a complimentary test to evaluate HER2 status to avoid haphazard treatment with trastuzumab in negative cases and identifying positive cases for suitable treatment.
\end{abstract}

\section{* Corresponding Author:}

Hossein Teimori, PhD.

Address: Cellular and Molecular Research Center, Shahrekord University of Medical Sciences, Rahmatieh, Shahrekord, Iran.

Phone: +98 (38) 33331471

E-mail: hosseintimm@yahoo.com 


\section{Introduction}

$\boldsymbol{H}$

$E R 2$ gene also referred to as erbB2 or neu, is a proto-oncogene located on the chromosomal region $17 \mathrm{q} 12$. This gene produces a protein responsible for controlling some of the important activates of the cells, including cell multiplication and survival [1]. The protein is a member of the epidermal growth factor receptor (EGFR) family that includes four receptors: HER1, HER2, HER3, and HER4 [2]. All the receptors in this family, except $H E R 3$, share the same physiological characteristics such as extracellular ligand-binding domain (including domain I, II, III, IV), hydrophobic membrane-spanning region, intracellular tyrosine kinase domain flanked by a juxtamembrane domain, and carboxyl-terminal tail with tyrosine autophosphorylation sites [3]. Ligand binding to the receptors leads to the dimerization of the receptors. The cytosolic domain of the dimerized receptors phosphorylates each other at specific tyrosine residues which lead to the activation of the receptors [4].

Activated receptors stimulate downstream signaling pathways and play a significant role in cell development, proliferation, and differentiation. These effects are mediated via pathways such as MAPK (mitogen-activated protein kinase), PI3K/AKT (phosphatidylinositol 3-kinase (PI3K)/protein kinase B [AKT]), and phospholipase pathway [5]. The development of different cancer, including breast tumors, is mediated by abnormal expression and signaling of these receptors. Therefore, HER receptors are considered as eligible therapeutic targets for many cancers [6]. Overexpression of HER2, due to aberrant gene amplification or transcription, could be detected in $20-30 \%$ of breast cancers which results in increased cell proliferation, and cell survival and diminution of cell mortality; all of which correlate with poor prognosis, highly aggressive and metastasis nature of such tumors and their resistance to conventional therapies including hormone therapy, radiation and certain types of chemotherapy [7-9]. Treatment of HER2 positive breast cancers is usually performed using a humanized version of murine mAb $4 \mathrm{D} 5$ against HER2 receptors called trastuzumab [10].

Trastuzumab is an effective treatment only in patients whose tumors are positive for HER2 gene amplification. Some patients do not respond to trastuzumab or acquire resistance to trastuzumab. For this reason, other drugs such as lapatinib, pertuzumab, and neratinib have been developed for the treatment of HER2 positive breast cancer [11]. Among the predictive and prognostic factors in breast cancer, assessment of HER 2 for the prognosis and therapeutic decision of breast cancer patients is a vital step at the time of clinical examination.

The assessment of HER 2 can be performed at three levels; examination of protein, mRNA, and DNA. Immunohistochemistry (IHC) and ELISA examine HER2 status at the protein level. qRT PCR and microarray are used for the assessment of HER2 at the RNA level. FISH (fluorescence in situ hybridization), CISH (chromogenic in situ hybridization), SISH (silver-enhanced in situ hybridization), southern blot, and MLPA (multiplex ligation-dependent probe amplification) are some of the techniques for HER2 status assessment at the DNA level [12]. FISH and IHC are the most common methods which are used for HER2 status evaluation in breast cancer [13]. IHC is a specific technique that uses fluorescent or enzyme tagged antibodies (monoclonal or polyclonal) to detect the presence and distribution of target antigens in the studied samples [14].

Despite the low cost of the IHC test, it has some limitations, such as the variability of antibody specificity and sensitivity, and discrepancy in the interpretation of the result. These problems can be circumvented by FISH analysis [15]. FISH determines the copy number of the gene and IHC evaluates the protein expression level. IHC analysis is a routine, easy, relatively quick, and costeffective technique that involves the detection of HER receptors on the cell membrane in tissue using polyclonal or monoclonal antibodies. In this system, scoring is semi-quantitative and the extent of membrane staining determines the score on a scale from 0-3. According to the ASCO/CAP guideline, staining scores of 0 and $1^{+}$are negative, $2^{+}$is interpreted as ambiguous and $3^{+}$is considered positive. Tissue handling, fixation method, sensitivity, and specify of antibody, and the scoring criteria are some variables that could affect IHC result [15].

FISH seems to be more objective and accurate than IHC and is a clinically verified replacement for IHC. In this method, a fluorescently labeled probe is added to the tissue section which is hybridized with its target gene in the nucleus of the cells. To determine the amplification status of the $H E R 2$ gene, the relative fluorescent emission of HER 2 signals to the chr17 signals per cell nucleus was used for scoring [16]. According to the standard guidelines of ASCO/CAP, if the ratio of HER2 to CEP17 is greater than 2.2, HER2 gene amplification has occurred in the cells. On the other hand, if the ratio is less than 1.8, HER2 gene amplification has not occurred. Finally, if the ratio of HER2/CEP17 is between 1.8 and 2.2, it is considered ambiguous [15]. In this study, our purpose 
was to estimate the relative proliferation of HER2 gene in patients suffering from infiltrating breast cancer, using FISH, and compare these findings with IHC results.

\section{Materials and Methods}

\section{Tumor specimens}

Tissue specimens of invasive breast carcinomas from 46 patients were used in this study. The Institutional Ethics Committee of Shahrekord University of Medical Sciences, Shahrekord City approved this study (Code: 90-8-5). Standardized written consent was obtained from all patients and they were given the information regarding the purpose of the study and data that would be published.

The characteristics of patients' tumors, including type, grade, and size of the tumors, as well as the status of lymph node and the personal information of the patients (e.g., age), if possible, were provided for the participants. The Zytolight SPEC HER2/CEN17 kit (ZytoVision, Bremerhaven, Germany) was used for identifying HER2 gene status. This kit contains two different probes. The green-labeled probe (ZyGreen) targets the HER2 gene and the other one which contains orange-labeled polynucleotides (ZyOrange) targets tandemly repeating DNA sequences of the centromere of chromosome 17, known as alpha satellite sequences.

\section{Immunohistochemistry (IHC) analysis}

The patients who participated in the present study were previously referred to Dr. Faghihi's Pathological Lab (Isfahan, Iran) to perform the IHC test, for determining their HER2 status. The results of their IHC analysis are used in this study to compare them with the obtained data from the FISH test.

\section{FISH analysis}

The FISH procedure was performed using the manufacturer's instruction. A fluorescent microscope (Olympus BX5) equipped with appropriate filters was used to evaluate the intensity of the lights emitted from fluorescent-labeled probes. Firstly, the specimens were spliced as $4-\mu \mathrm{m}$ sections and were laid onto saline-coated slides. After 10 minutes of incubation at $70^{\circ} \mathrm{C}$, the slides were deparaffinized in xylem (Merck KGaA, Darmstadt, Germany) for $2 \times 10$ minutes. A concentration gradient of ethanol $(100 \%, 100 \%, 90 \%, 70 \%)$ was applied to dehydrate the samples followed by immersing the slides in the pretreatment solution citric at $98^{\circ} \mathrm{C}$ for 15 minutes.
After washing the slides in distilled water for $2 \times 2$ minutes and drawing of the liquids, tissue sections were exposed to pepsin solution. Subsequently, the slides were kept in a humidity chamber for 10 minutes. Following enzymatic digestion, the slides were rinsed with SSC buffer for 5 minutes and then submerged for 1 minute in distilled water. Thereinafter the slides were dehydrated in $70 \%, 90 \%$, and $100 \%$ ethanol solutions, each for 1 minute. The digestion degree of slides was determined by applying $10 \mu \mathrm{L}$ of 4, 6-diamidino 2-phenylindole (DAPI) solution, and the quality of the slides was assessed with a fluorescent microscope.

After pretreatment, the solution containing the probes of HER2 and centromere of chromosome 17 was applied. After placing coverslips on the slides, for denaturing the chromosomes, they were heated at $75^{\circ} \mathrm{C}$ for 10 minutes and incubated overnight at $37^{\circ} \mathrm{C}$ in a humidity chamber. After hybridization, the slides were treated with a $1 \mathrm{x}$ washing buffer for $2 \times 5$ minutes at $37^{\circ} \mathrm{C}$. By using a gradient series of ethanol $(70 \%, 90 \%, 100 \%)$ each for 1 minute, the slides were dehydrated and air dried. Finally, by applying $30 \mu \mathrm{L}$ of DAPI, the slides were counterstained. Olympus BX5 fluorescence microscope (Olympus, Tokyo, Japan) was used to analyze the fluorescence emission of the probes. The ratio of HER2 signal to the CEP17 signal was measured in the nuclei of 40 cells, which were morphologically intact and separate. HER2 to CEP17 ratio greater than 2.2 was interpreted as an indication of HER2 gene multiplication.

\section{Statistical analysis}

The Chi-squared test, with a significant level of 0.05 , fulfilled to assess the association between HER2 status and other pathological and clinical characteristics.

\section{Results}

\section{FISH results}

HER2 gene duplication in the formalin-fixed paraffinembedded tissue specimens was detected by FISH (Figure 1). In 12 cases $(26 \%)$, the amplification of the HER2 gene was detected while in the other 34 samples (74\%), no multiplication of the gene was detected. The equivocal FISH results were not found in the present study. In Table 1, the personal information of the patients and their tumor characteristics are shown. 

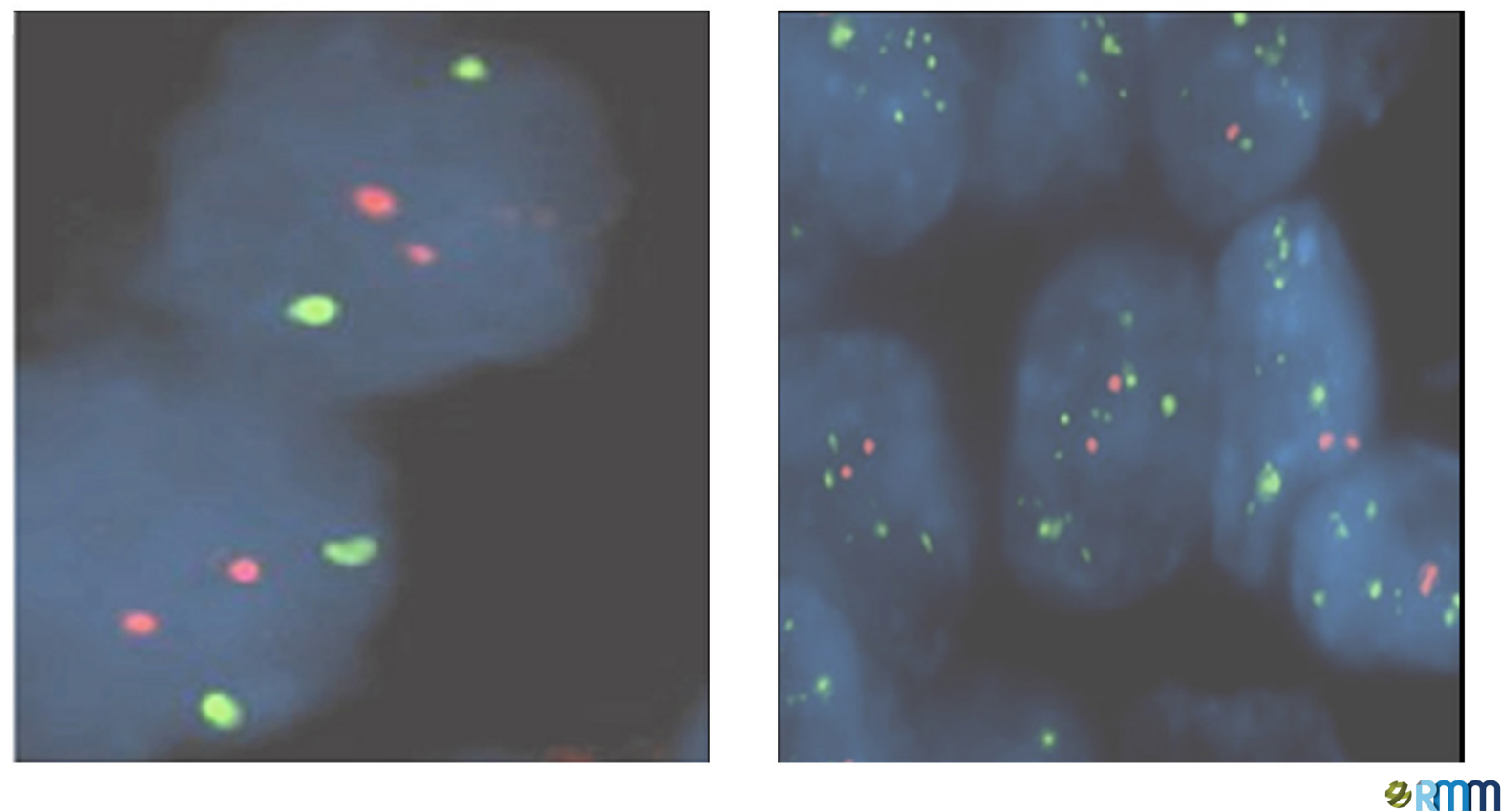

Figure 1. The results of the FISH analysis for HER2 gene amplification. Left: negative HER2 amplification; the ratio of HER2 (green) to CEP17 (red) is less than 2.2. Right: positive HER2 amplification. The ratio of HER2/CEP17 is more than 2.2.

\section{IHC results}

The IHC analysis of HER 2 protein was evaluated in 31 patients. Fourteen cases had an IHC score of $0 / 1^{+}, 11$ cases had an IHC score of $2^{+}$, and 6 cases had an IHC score of $3^{+}$.

\section{Comparison of the two assays}

On the whole, considerable concordance was seen between the results of these two tests (IHC and FISH) in 22 patients. Ten and 12 cases were detected as positive and

Table 1. Information regarding the tumor characteristics of 46 patients with invasive breast cancer

\begin{tabular}{|c|c|c|}
\hline \multicolumn{2}{|c|}{ Characteristic } & \multirow{2}{*}{$\begin{array}{c}\text { No. (\%) } \\
30(65.2)\end{array}$} \\
\hline \multirow{3}{*}{ Age (y) } & $\leq 50$ & \\
\hline & & \\
\hline & $>50$ & $16(34.8)$ \\
\hline \multirow{3}{*}{ Tumor size $(\mathrm{cm})$} & $<2$ & $17(37)$ \\
\hline & $\geq 2$ & $20(43.5)$ \\
\hline & Uncertain & $19(19.5)$ \\
\hline \multirow{3}{*}{ Histological type } & Ductal & $29(63)$ \\
\hline & Lobular & $7(15.2)$ \\
\hline & Other & $10(21.7)$ \\
\hline \multirow{5}{*}{ Histological grade } & Grade 1 & $5(10.9)$ \\
\hline & Grade 2 & $19(41.3)$ \\
\hline & & \\
\hline & Grade 3 & $15(32.6)$ \\
\hline & Uncertain & $7(15.2)$ \\
\hline \multirow{3}{*}{ Lymph node status } & Positive & $20(43.5)$ \\
\hline & Negative & $14(30.14)$ \\
\hline & Uncertain & $12(26.1)$ \\
\hline
\end{tabular}


Table 2. The correlation between tumor grade and HER2 gene amplification

\begin{tabular}{|c|c|c|c|c|}
\hline \multirow{2}{*}{ Tumor Grade } & \multirow{2}{*}{ No. } & \multicolumn{2}{|c|}{ No. (\%) } & \multirow{2}{*}{$\mathbf{P}$} \\
\hline & & With HER2 Amplification & Without HER2 Amplification & \\
\hline Grade 1 & 5 & $0(0)$ & $5(100)$ & NS \\
\hline Grade 2 & 19 & $4(21.05)$ & 15 (78.95) & 0.02 \\
\hline Grade 3 & 15 & $8(53.33)$ & $7(46.66)$ & NS \\
\hline
\end{tabular}

NS: Not significant

negative by either two methods, respectively. As a result, $80 \%$ of concordance was seen between these two methods. Based on the IHC test, 14 specimens were detected as IHC $0 /+1$. But FISH analysis confirmed that only 12 of them had no gene amplification and the results for the two remaining samples were opposite. Gene amplification was detected in these two cases by FISH, but could not be detected by IHC. IHC test, assigned 11 specimens to IHC $2+$. On the other hand, the FISH analysis showed that only 4 samples had HER 2 amplification and the gene amplification was not detected in the remaining 7 samples.

These results exhibited $36.36 \%$ concordance between IHC and FISH for the $2+$ group. In a group of patients whose protein evaluation by IHC was measured as $3+$, HER 2 gene amplification was also observed by FISH in all cases in this group, indicating a $100 \%$ concordance between the results of these two methods. In particular, gene amplification in 4 cases in this group was high and the signals were seen in cluster form. The FISH results were negative in 12 cases which assigned to $0 / 1+$ group by IHC and were positive in 2 cases that showed $85.71 \%$ concordance (Table 2). Statistical analysis showed a correlation between HER2 status and tumor grade $(\mathrm{P}=0.02)$ and tumors with HER2 gene amplification had high pathological grade (Table 2). In ductal carcinoma, the amplification of the HER2 gene was more frequent than other types of breast cancer (83.3\%); however, no association was observed between HER2 status and the tumor type. No correlation was observed between HER2 status and the size of the tumor, lymph node characteristics, and the age of patients.

\section{Discussion}

Assessment of HER2 status is an essential factor for the prognosis and management of breast cancer [12]. Studies have shown that the amplification and overexpression of HER2 gene in breast cancer are associated with poor prognosis of the diseases and patients with HER2 positive breast cancer are shown to have shorter disease-free and overall survival than patients with normal HER2 status $[17,18]$. Besides, HER2 status predicts response to HER2 targeted therapy and other cancer therapies. HER2 positive tumors respond better to anthracycline chemotherapy and also HER2 positive status is associated with hormone therapy resistance [19-21].

Due to prognostic and predictive significance, HER2 is a target for drug development. Trastuzumab is a monoclonal antibody targeted against the extracellular part of HER2 protein which has been shown to noticeably increase the life expectancy of HER2 positive breast cancer patients [22]. Therefore, a precise evaluation of HER2 status is necessary for identifying patients who may benefit from trastuzumab therapy [23]. The most common techniques for the assessment of HER2 status are FISH and IHC. These two methods are supplementary for HER2 status assessment so that the former evaluates the DNA level and the latter at the protein level [24]. IHC method is fairly quick and cost-effective but several factors influence the accuracy of the results, such as inter-observer variability and factors influencing the tissue fixation process [25]. FISH is a quick, precise, and reproducible method for HER2 status assessment and is more objective and quantitative than IHC [26].

In the present study, HER2 status was evaluated in invasive breast cancer samples by two separate methods of IHC and FISH. Then a complete comparison was performed between the FISH results and the relevant results of IHC. We found $100 \%$ concordance between FISH and IHC results in cases of IHC score $3^{+}$, which showed high sensitivity of IHC for cases with a high level of protein overexpression and verify findings of other studies that reported over $90 \%$ concordance [27]. In this study, $36.36 \%$ of cases with IHC score $2^{+}$showed gene amplification. In other studies, the prevalence of gene amplification in IHC score $2^{+}$cases has been reported $6 \%-25 \%$ [28]. This finding reveals that many cases with IHC score $2^{+}$lack gene amplification and are false positive. This concordance rate is similar to findings obtained by Kakar et al. that reported 35\% concordance in this group [29]. 
A possible explanation for this discordant is the overexpression of the protein without gene amplification that is a very rare occurrence and is seen in only $\leq 3 \%$ of cases. About $14.8 \%$ of cases with an IHC score of $0 / 1^{+}$showed gene amplification. This discordance may be due to a low level of gene amplification and gene transcription resulting in a low level of HER 2 protein production [30]. In the present study, statistical analysis showed concordance between HER2 status and histological tumor grade while similar results are reported by Yau et al. [31]. Also, Biliuos et al. found that the amplification of the HER2 gene was prevalent in patients with breast cancer who were diagnosed at the grade II and III of the disease (97\%) [32].

The present study showed that in patients with infiltrating ductal carcinoma, the multiplication of HER2 gene was more frequent, but no significant correlation was seen between tumor type and the status of HER2. The studied population may not have been large enough to detect this correlation. No meaningful correlation was detected between the patients' age, tumor size, and the characteristics of lymph nodes. These findings are in agreement with the results obtained by Panjwani et al. [33]. The findings of this study indicate that FISH is a robust and accurate method for the evaluation of HER2 status compared to IHC analysis. In particular, the results of IHC are not reliable in cases with IHC score of $2^{+}$because many of these cases are false positive and trastuzumab therapy is not efficacious for this group of patients. In other words, these patients do not need trastuzumab for therapy. Therefore, it is inevitable to perform a complementary test in patients with IHC score of $2^{+}$to avoid haphazard treatment with trastuzumab in negative cases and recognizing positive cases for suitable treatment.

The research data also suggest that IHC could be a reliable method in cases with IHC score of $0 / 1^{+}$and $3^{+}$since high concordance was observed between the results of FISH and those of IHC. With regard to the results of this research and previous studies, since the HER2 gene multiplication is related to the poor prognosis of breast cancer tumors with high pathological grade, it is suggested that performing FISH assay, which is more reliable than IHC, help physicians to determine the best treatment for these patients.

\section{Ethical Considerations}

\section{Compliance with ethical guidelines}

All ethical principles are considered in this article.

\section{Funding}

This research was supported by Shahrekord University of Medical Sciences, Shahrekord, Iran (Research Grant: 1237).

Authors' contributions

All authors were equally contributed in preparing this article.

\section{Conflict of interest}

The authors declared no conflict of interest.

\section{Acknowledgements}

We gratefully thank the Cellular and Molecular Research Center of Shahrekord for their technical assistance and Biology Department of Isfahan University for verifying the project.

\section{References}

[1] Abrahao-Machado LF, Scapulatempo-Neto C. HER2 testing in gastric cancer: An update. World J Gastroenterol. 2016; 22(19):4619. [DOI:10.3748/wjg.v22.119.4619] [PMID] [PMCID]

[2] Hayes DF. HER2 and breast Cancer: A phenomenal success story. N Engl J Med. 2019; 381(13):1284-6. [DOI:10.1056/NEE JMcibr1909386] [PMID]

[3] Jácome AAA, Wohnrath DR, Neto CS, Carneseca EC, Serrano SV, Viana LS, et al. Prognostic value of epidermal growth factor receptors in gastric cancer: A survival analysis by Weibull model incorporating long-term survivors. Gastric Cancer. 2014; 17(1):76-86. [DOI:10.1007/s10120-013-0236-z] [PMID] [PMCID]

[4] Bragin PE, Mineev KS, Bocharova OV, Volynsky PE, Bocharov EV, Arseniev AS. HER2 transmembrane domain dimerization coupled with self-association of membrane-embedded cytoplasmic juxtamembrane regions. Am J Mol Biol 2016; 428(1):52-61. [DOI:10.1016/j.jmb.2015.11.007] [PMID]

[5] Dittrich A, Gautrey H, Browell D, Tyson-Capper A. The HER2 signaling network in breast cancer-like a spider in its web. J Mammary Gland Biol Neoplasia. 2014; 19(3-4):253-70. [DOI:10.1007/s10911-014-9329-5] [PMID]

[6] Saxena R, Dwivedi A. ErbB family receptor inhibitors as therapeutic agents in breast cancer: current status and future clinical perspective. Med Res Rev. 2012; 32(1):166-215. [DOI:10.1002/med.20209] [PMID]

[7] Zhu X, Wu L, Qiao H, Han T, Chen S, Liu X, et al. Autophagy stimulates apoptosis in HER 2-overexpressing breast cancers treated by lapatinib. J Cell Biochem. 2013; 114(12):2643-53 [DOI:10.1002/jcb.24611] [PMID] 
[8] Rexer BN, Arteaga CL. Intrinsic and acquired resistance to HER2-targeted therapies in HER2 gene-amplified breast cancer: mechanisms and clinical implications. Crit Rev ${ }^{\mathrm{TM}} \mathrm{On}-$ cog. 2012; 17(1):1-16.. [DOI:10.1615/CritRevOncog.v17.i1.20] [PMID]

[9] Fiszman GL, Jasnis MA. Molecular mechanisms of trastuzumab resistance in HER2 overexpressing breast cancer. Int J Breast Cancer. 2011; 2011. [DOI:10.4061/2011/352182] [PMID] [PMCID]

[10] Baselga J, Cortés J, Kim S-B, Im S-A, Hegg R, Im Y-H, et al Pertuzumab plus trastuzumab plus docetaxel for metastatic breast cancer. N Engl J Med. 2012; 366(2):109-19. [DOI:10.1056/ NEJMoa1113216] [PMID] [PMCID]

[11] Mukai H. Treatment strategy for HER2-positive breast cancer. Int J Clin Oncol. 2010; 15(4):335-40. [DOI:10.1007/s10147-0100107-0] [PMID]

[12] Moelans C, De Weger R, Van der Wall E, Van Diest P. Current technologies for HER2 testing in breast cancer. Crit Rev Oncol Hematol. 2011; 80(3):380-92. [DOI:10.1016/j.crii trevonc.2010.12.005] [PMID]

[13] Perez EA, Cortés J, Gonzalez-Angulo AM, Bartlett JM. HER2 testing: Current status and future directions. Cancer Treat Rev. 2014; 40(2):276-84. [DOI:10.1016/j.ctrv.2013.09.001] [PMID]

[14] Duraiyan J, Govindarajan R, Kaliyappan K, Palanisamy M. Applications of immunohistochemistry. J Pharm Bioallied Sci. 2012; 4(Suppl 2):S307. [DOI:10.4103/0975-7406.100281] [PMID] [PMCID]

[15] Wolff AC, Hammond MEH, Schwartz JN, Hagerty KL, Allred DC, Cote RJ, et al. American Society of Clinical Oncology/ College of American Pathologists guideline recommendations for human epidermal growth factor receptor 2 testing in breast cancer. Arch Pathol Lab Med. 2007; 131(1):18-43.

[16] Penault-Llorca FDR, Bilous M, Dowsett M, Hanna W, Osamura RY, Rüschoff J, et al. Emerging technologies for assessing HER2 amplification. Am J Clin Pathol. 2009; 132(4):539-48. [DOI:10.1309/AJCPV2I0HGPMGBSQ] [PMID]

[17] Figueroa-Magalhães MC, Jelovac D, Connolly RM, Wolff AC Treatment of HER2-positive breast cancer. The Breast. 2014; 23(2):128-36. [DOI:10.1016/j.breast.2013.11.011] [PMID] [PMM CID]

[18] Frogne T, Laenkholm A-V, Lyng MB, Henriksen KL, Lykkesfeldt AE. Determination of HER2 phosphorylation at tyrosine $1221 / 1222$ improves prediction of poor survival for breast cancer patients with hormone receptor-positive tumors. Breast Cancer Res. 2009; 11(1):R11. [DOI:10.1186/bcr2230] [PMID] [PMCID]

[19] Dhesy-Thind B, Pritchard KI, Messersmith H, O'Malley F, Elavathil L, Trudeau M. HER2/neu in systemic therapy for women with breast cancer: A systematic review. Breast Cancer Res Treat. 2008; 109(2):209-29. [DOI:10.1007/s10549-0079656-y] [PMID]

[20] Colomer R, Llombart-Cussac A, Lloveras B, Ramos M, Mayordomo JI, Fern $\tilde{A}_{j}$ ndez R, et al. High circulating HER2 extracellular domain levels correlate with reduced efficacy of an aromatase inhibitor in hormone receptor-positive metastatic breast cancer: A confirmatory prospective study. Cancer. 2007; 110(10):2178-85. [DOI:10.1002/cncr.23043] [PMID]
[21] Miyoshi Y, Kurosumi M, Kurebayashi J, Matsuura N, Takahashi M, Tokunaga E, et al. Predictive factors for anthracycline-based chemotherapy for human breast cancer. Breast Cancer. 2010; 17(2):103-9. [DOI:10.1007/s12282-009-0152-6] [PMID]

[22] Álvarez RH. Present and future evolution of advanced breast cancer therapy. Breast Cancer Res. 2010; 12(2):S1. [DOI:10.1186/bcr2572] [PMID] [PMCID]

[23] Dawood S, Broglio K, Buzdar AU, Hortobagyi GN, Giordano SH. Prognosis of women with metastatic breast cancer by HER2 status and trastuzumab treatment: An institutionalbased review. J Clin Oncol. 2010; 28(1):92. [DOI:10.1200/ JCO.2008.19.9844] [PMID] [PMCID]

[24] Cuadros M, Villegas R. Systematic review of HER2 breast cancer testing. Appl Immunohistochem Mol Morphol. 2009; 17(1):1-7. [DOI:10.1097/PAI.0b013e318169fc1c] [PMID]

[25] Brügmann A, Lelkaitis G, Nielsen S, Jensen KG, Jensen V. Testing HER2 in breast cancer: a comparative study on BRISH, FISH, and IHC. Appl Immunohistochem Mol Morphol. 2011; 19(3):203-11. [DOI:10.1097/ PAI.0b013e3181f7118e] [PMID]

[26] Shah S, Chen B. Testing for HER2 in breast cancer: A continuing evolution. Patholog Res Int. 2011; 2011. [DOI:10.4061/2011/903202] [PMID] [PMCID]

[27] Mrozkowiak A, Olszewski WP, Piascik A, Olszewski WoT. HER2 status in breast cancer determined by IHC and FISH: Comparison of the results. Pol J Pathol. 2004; 55(4):165-71.

[28] Yaziji H, Goldstein LC, Barry TS, Werling R, Hwang H, Ellis GK, et al. HER-2 testing in breast cancer using parallel tissue-based methods. J Am Med Assoc. 2004; 291(16):1972-7. [DOI:10.1001/jama.291.16.1972] [PMID]

[29] Kakar S, Puangsuvan N, Stevens JM, Ascp RSMT, Mangan G, Sahai S, et al. HER-2/neu assessment in breast cancer by immunohistochemistry and fluorescence in situ hybridization: Comparison of results and correlation with survival. Mol Diagn. 2000; 5(3):199-207. [DOI:10.1054/ modi.2000.16689] [PMID]

[30] Birner P, Oberhuber G, Stani J, Reithofer C, Samonigg H, Hausmaninger $\mathrm{H}$, et al. Evaluation of the United States Food and Drug Administration-approved scoring and test system of HER-2 protein expression in breast cancer. Clin Cancer Res. 2001; 7(6):1669-75.

[31] Yau TK, Sze H, Soong IS, Hioe F, Khoo US, Lee AWM. HER2 overexpression of breast cancers in Hong Kong: prevalence and concordance between immunohistochemistry and in-situ hybridisation assays. Hong Kong Med J. 2008; 14(2):130.

[32] Bilous M, Ades C, Armes J, Bishop J, Brown R, Cooke B, et al. Predicting the HER2 status of breast cancer from basic histopathology data: An analysis of 1500 breast cancers as part of the HER2000 International Study. Breast. 2003, 12(2):92-8. [DOI:10.1016/S0960-9776(02)00273-4]

[33] Panjwani P, Epari S, Karpate A, Shirsat H, Rajsekharan P, Basak R, et al. Assessment of HER-2/neu status in breast cancer using fluorescence in situ hybridization \& immunohistochemistry: Experience of a tertiary cancer referral centre in India. IIndian J Med Res. 2010; 132(3):287-95. 
This Page Intentionally Left Blank 